\title{
Oringual syut \\ Does COX1 gene polymorphism (A842G/C50T) influence peptic ulcer bleeding in Indian patients?
}

\author{
S. Santhosh, Ebby George Simon, AJ Joseph, Amit Kumar Dutta, \\ Sudipta Dhar Chowdhury, Reuben Thomas Kurien, Ashok Chacko
}

\section{ABSTRACT}

Molecular Medicine Unit, Division of Gastrointestinal Sciences,

Christian Medical College, Vellore, Tamil Nadu, India

\section{Correspondence:}

Dr. S. Santhosh,

Email: sunsanthosh@gmail.com
This is a pilot study to test the hypothesis that polymorphisms that may be linked to cyclooxygenase production may affect the likelihood and the nature of bleeding in patients with ulcer disease. Of the two polymorphism that have previously been studied for links we chose the $\mathrm{A} 842 \mathrm{G}$ polymorphims. Of the 50 patients with ulcer bleeding who were studied, 8 had a heterozygous polymorphisms and 42 had the normal configuration. On comparing these two groups. there were no significant differences in clinical presentation except that there was a tendency to have less gastric ulcers among those with the A842G/C50T polymorphism. Based on these studies we need to undertake a larger studies comparing these groups with those with ulcers without GI bleeding and those without ulcers

KEYWORDS: COX1 gene, polymorphism, peptic ulcer bleed.

\section{Introduction}

Peptic ulcer bleeding continues to be the most common cause of significant upper gastrointestinal bleeding seen in clinical practice. ${ }^{1}$ Among the different predisposing factors resulting in peptic ulcer and thereby peptic ulcer bleeding, H. pylori infection and non-steroidal anti-inflammatory drugs (NSAIDs) rank foremost. ${ }^{2,3}$ The enzyme cyclooxygenase (COX) that helps in the conversion of arachidonic acid to prostaglandins (PG) is inhibited by NSAIDs (including aspirin) and thereby causes peptic ulcer. ${ }^{4}$ Between the two isoforms of COX, the gastric mucosa is rich in COX-1 where it helps in PG synthesis, which in turn helps in maintaining the integrity of the gastric epithelial barrier and mucus secretion. COX-1 gene polymorphisms are thought to inhibit PG synthesis and therefore contribute to the pathogenesis of peptic ulcer. Limited studies have been conducted to study the association of COX-1 (A842G/C50T) gene polymorphisms with peptic ulcer disease. ${ }^{5,6}$ The relationship between COX-1 gene polymorphisms and peptic ulcer bleeding in Indian population has not been previously reported.

The aim of this pilot study was to investigate the influence of specific COX-1 gene polymorphisms (A842G/C50T) on the occurrence of peptic ulcer bleeding as observed in our hospital which is a tertiary care centre in South India.

\section{Methods}

Patients older than 16 years who underwent an upper gastrointestinal (UGI) endoscopy at the Christian Medical 
College, Vellore, South India for bleeding peptic ulcer from January $1^{\text {st }} 2007$ to July $31^{\text {st }} 2009$ were invited to participate in the study. We collected information about clinical presentation, use of NSAIDs (including aspirin), clopidogrel and anticoagulants; presence of comorbidities, endoscopic findings and type of endotherapy, outcome measures like rebleeding, transfusion requirement, need for admission, intensive unit care and death. The stigmata of recent hemorrhage as defined by Forrest classification were used to group the lesions into high and low risk lesions, the high risk included Ia, Ib, IIa \& IIb while low risk lesions included IIc \& III. ${ }^{7}$

Blood samples were drawn from the patients for genetic

Table 1: Characteristics of peptic ulcer bleeders with different COX-1 A842G/C50T polymorphisms

\begin{tabular}{|c|c|c|c|}
\hline & Heterozygous & Wild type & $\overline{P \text { value }}$ \\
\hline Number (\%) & $8(16)$ & $42(84)$ & \\
\hline Mean age (SD) years & $45.1(22.2)$ & $52.1(15.14)$ & 0.422 \\
\hline $\mathrm{M}: \mathrm{F}$ & $8: 0$ & $33: 9$ & \\
\hline Abdominal pain (\%) & $5(62.5)$ & $12(28.6)$ & 0.102 \\
\hline Hematemesis (\%) & $6(75)$ & $32(76.2)$ & 1 \\
\hline Melena (\%) & $4(50)$ & $27(64.3)$ & 0.459 \\
\hline Smoking (\%) & $2(25)$ & $13(31)$ & 1 \\
\hline Alcohol (\%) & $1(12.5)$ & $12(28.6)$ & 0.662 \\
\hline \multicolumn{4}{|l|}{ Medication (\%) } \\
\hline - NSAIDs & $4(50)$ & $18(42.9)$ & 0.718 \\
\hline - Clopidogrel & 0 & $4(9.5)$ & 1 \\
\hline - Anticoagulant & 0 & $2(4.8)$ & 1 \\
\hline \multicolumn{4}{|l|}{ Comorbidities (\%) } \\
\hline $\begin{array}{l}\text { Chronic obstructive } \\
\text { pulmonary disease }\end{array}$ & 0 & $4(9.5)$ & 1 \\
\hline - Chronic renal disease & 0 & $3(7.1)$ & 1 \\
\hline \multicolumn{4}{|l|}{ Clinical examination } \\
\hline - Mean pulse rate (SD) & $98.3(16.4)$ & $96.6(15)$ & 0.794 \\
\hline - Mean SBP(SD) & $116.3(20)$ & $115.7(25.8)$ & 0.583 \\
\hline - Mean DBP(SD) & $73.8(9.16)$ & $74.3(15.5)$ & 0.896 \\
\hline Diagnosis $(\%)$ & & & 0.126 \\
\hline - $\mathrm{GU}$ & $2(25)$ & $18(42.9)$ & \\
\hline - $\mathrm{DU}$ & $6(75)$ & $16(38.1)$ & \\
\hline - $\mathrm{GU}+\mathrm{DU}$ & $0(0)$ & 8 (19) & \\
\hline \multicolumn{4}{|l|}{$\underline{\text { Ulcer risk grade }(\%)}$} \\
\hline - High & $4(50)$ & $17(40.5)$ & 0.706 \\
\hline - Low & $4(50)$ & $25(59.5)$ & \\
\hline Rebleed (\%) & $1(12.5)$ & $3(7.1)$ & 0.514 \\
\hline Surgery (\%) & 0 & $1(2.4 \%)$ & 1 \\
\hline $\begin{array}{l}\text { Mean transfusion } \\
\text { requirement }(\mathrm{SD})\end{array}$ & $0.9(1.1)$ & $1(1.3)$ & 0.783 \\
\hline $\begin{array}{l}\text { Mean duration of } \\
\text { hospital stay(SD) }\end{array}$ & $6.9(9.7)$ & $4.9(6.1)$ & 0.591 \\
\hline ICU care $(\%)$ & $1(12.5)$ & $4(9.5)$ & 1 \\
\hline Death $(\%)$ & 0 & 0 & \\
\hline
\end{tabular}

SD: standard deviation, SBP:systolic blood pressure, DBP: diastolic blood pressure, GU: gastric ulcer, DU: duodenal ulcer, ICU: intensive care unit analysis after obtaining written informed consent. DNA was extracted from EDTA blood, using the Qiagen DNA extraction mini kit. Polymerase chain reation (PCR) and restriction fragment length polymorphism (RFLP) were employed to detect the polymorphism A842G/C50T in the COX-1 gene as described earlier. $^{5}$

The categorical variables were expressed as frequencies and percentages while the continuous variables were expressed as mean \pm standard deviation. Categorical variables were compared either using chi-square test or Fisher's exact test as appropriate while the continuous variables were compares using Mann-Whitney U test. A p-value $<0.05$ was considered significant. The statistical calculations were performed using the SPSS software (version17.0).

The study was conducted after approval by the institutional review board (IRB) of our hospital and written informed consent was obtained from the patients.

\section{Results}

Between January 1, 2007 to July 31, 2009, 109 patients who presented to our hospital were diagnosed with peptic ulcer bleed. Among them, 50 patients agreed to participate in the study. 8 (16\%) were found to be heterozygous for COX-1 A842G/ C50T mutation while the remaining $42(84 \%)$ had wild type mutation. The clinical characteristics and the outcome measures did not differ significantly among those with heterozygous and wild type mutations (Table 1).

Among the 50 patients with peptic ulcer bleeding, 21(42\%) had a high risk lesion while $29(58 \%)$ had a low risk lesion. The presence of the heterozygous mutation among high and low risk lesions ( $19 \%$ vs $13.8 \%, \mathrm{p}=0.706$ ) did not differ significantly.

\section{Discussion}

In view of the morbidity and mortality associated with peptic ulcer and its complications, researchers in understanding its pathogenesis have done considerable amount of work. From the genetic angle, there are some studies with respect to the association between gene polymorphisms and peptic ulcer disease. ${ }^{8}$ The role of COX-1 gene polymorphisms on peptic ulcer have been studied earlier. ${ }^{5,6}$ The COX 1 gene is composed of 11 exons of 22 kilobase size and encodes for a 576 amino acid long protein. ${ }^{9}$ At least 9 different single nuclear polymorphisms (SNP) have been identified within the COX-1 gene locus and among these; $\mathrm{A} 842 \mathrm{G}$ and C50T are found to be 
in complete linkage disequilibrium. A842G is located in the promoter of COX-1 and the Gallele creates a theoretic AP2 transcription factor site that might modify gene expression. The C50T encodes for a substitution (Pro17Leu) ${ }^{6}$ amino acidsproximal to the signal peptide cleavage site, which may cause protein mis-compartmentalization. ${ }^{5}$

Halushka et al had noted that healthy participants who were heterozygous for the A842G/C50Thaplotype showed significantly greaterinhibition of $\mathrm{PGH} 2$ formation by acetylsalicylic acid compared to common allelehomozygotes. ${ }^{10}$ Contrary to their expectation, Dutch researchers found that the A842G/ C50T mutation was less frequent in their bleeding peptic ulcer patients $(7 \%)$ when compared with controls (13\%)althoughthis was not statistically significant. ${ }^{5}$ Subsequently, a Japanese study did not find this polymorphism in their study population (in both peptic ulcer patients and healthy controls) although there was an association of another SNPT1676C with NSAID-induced peptic ulcer. ${ }^{6}$

We observed the influence of COX1 (A-842G/C50T) gene polymorphism on peptic ulcer bleeding in Indian patients with $16 \%$ being heterozygous for the same. The frequency of this mutation appears higher than that reported among Dutch patients (7\%). ${ }^{5}$ It would have been informative to test for the presence of the A842G/ C50T mutation among our healthy controls. Comparison of the clinical characteristics and the outcome measures between those with wild type and others with heterozygous mutations showed no significant difference. Moreover, there was no difference in the occurrence of the mutation among those with high and low risk peptic ulcer lesions.

The study was limited by the fact it was done in a tertiary care centre and being subject to referral bias, it was not representative of the burden of the disease in the general population. The small number of patients involved could also explain the non-significant results obtained.

In conclusion, this pilot study suggests the existence of the COX1 (A842G/C50T) gene polymorphism in Indians presenting with peptic ulcer bleeding, although its role in influencing the latter appears minimal. Future studies are needed utilizing larger sample size and also to understand the contribution of other mutations to the occurrence of peptic ulcer bleeding.

\section{Acknowledgement}

We thank Dr Joost P H Drenth, Department of Molecular Gastroenterology and Hepatology, Radboud University, Nijmegen Medical Centre, Nijmegen, Netherlands who provided the primers used in the study and the fluid research committee, Christian Medical College, Vellore for the grant to conduct the same.

\section{References}

1. Hearnshaw SA, Logan RFA, Lowe D, Travis SPL, Murphy MF, Palmer KR. Acute upper gastrointestinal bleeding in the UK: patient characteristics, diagnoses and outcomes in the 2007 UK audit. Gut. 2011;60:1327-35.

2. Hunt RH, Malfertheiner P, Yeomans ND, Hawkey CJ, Howden $\mathrm{CW}$. Critical issues in the pathophysiology and management of peptic ulcer disease. Eur J Gastroenterol Hepatol. 1995;7:685-99.

3. Hallas J, Lauritsen J, Villadsen HD, Gram LF. Nonsteroidal antiinflammatory drugs and upper gastrointestinal bleeding, identifying high-risk groups by excess risk estimates. Scand. J. Gastroenterol. 1995;30:438-44.

4. McCarthy DM. Mechanisms of mucosal injury and healing: the role of non-steroidal anti-inflammatory drugs. Scand. J. Gastroenterol. Suppl. 1995;208:24-9.

5. van Oijen MGH, Laheij RJF, Koetsier M, de Kleine E, Te Morsche RHM, van Kerkhoven LAS, et al. Effect of a specific cyclooxygenase-gene polymorphism $(\mathrm{A}-842 \mathrm{G} / \mathrm{C} 50 \mathrm{~T})$ on the occurrence of peptic ulcer hemorrhage. Dig. Dis. Sci. 2006;51:2348-52.

6. Arisawa T, Tahara T, Shibata T, Nagasaka M, Nakamura M, Kamiya Y, et al. Association between genetic polymorphisms in the cyclooxygenase-1 gene promoter and peptic ulcers in Japan. Int. J. Mol. Med. 2007;20:373-8.

7. Forrest JA, Finlayson ND, Shearman DJ. Endoscopy in gastrointestinal bleeding. Lancet. 1974;2:394-7.

8. Shiotani A, Sakakibara T, Nomura M, Yamanaka Y, Nishi R, Imamura $\mathrm{H}$, et al. Aspirin-induced peptic ulcer and genetic polymorphisms. J. Gastroenterol. Hepatol. 2010;25:S31-4.

9. Kraemer SA, Meade EA, DeWitt DL. Prostaglandin endoperoxide synthase gene structure: identification of the transcriptional start site and 5'-flanking regulatory sequences. Arch Biochem Biophys. 1992;293:391-400.

10. Halushka MK, Walker LP, Halushka PV. Genetic variation in cyclooxygenase 1: effects on response to aspirin. Clin Pharmacol Ther. 2003;73:122-30. 